\title{
Prototype Komersial Kursi Borobudur Menuju Hilirisasi Dengan Pendekatan Gaya Eklektik
}

\author{
Rahmanu Widayat ${ }^{1}$, Anung B. Studyanto ${ }^{2}$ \\ ${ }^{12}$ Program Studi Desain Interior, Fakultas Seni Rupa dan Desain, Universitas Sebelas Maret, \\ Surakarta, Indonesia \\ ${ }^{1}$ rahmanuwidayat@staff.uns.ac.id
}

Artikel ini berlatar belakang eksplorasi hasil rekonstruksi Kursi Borobudur berupa replika yang mengacu pada kursi yang terdapat pada relief Karmawibhangga Candi Borobudur (tahun 2015) untuk menuju hilirisasi tahap 2, tahun 2020. Persoalannya adalah 1) Apa itu prototype Kursi Borobudur yang dapat menuju hilirisasi? 2) Mengapa prototype Kursi Borobudur menuju hilirisasi? 3) Bagaimana wujud Kursi Borobudur yang dapat menuju hilirisasi? Untuk mendapatkan jawaban dari persoalaan ini dilakukan penelitian secara kualitatif, dengan proses redesain (penciptaan) dengan pertimbangan aspek desain (pendekatan eklektik) dalam konteks budaya, dan industri kreatif yang harapannya dapat dirasakan manfaatnya bagi masyarakat dan dunia usaha (hilirisasi). Hasil dan pembahasannya adalah berbagai prototype komersial kursi Borobudur yang siap diproduksi dalam jumlah banyak dalam bidang industri kerajinan furniture. Keunggulannya terletak pada kombinasi berbagai jenis kayu, stacking chair (dapat ditumpuk), multi fungsi (kursi samping meja, kursi tamu, kursi makan, kursi pertemuan). Kesimpulannya kursi yang dikembangkan dari relief Candi Borobudur dapat disesuaikan dengan perkembangan zaman sekarang. Saran untuk penelitian selanjutnya bekerjasama sama dengan industri furniture dalam memproduksi kursi Borobudur terkait dengan hilirisasi.

Kata Kunci: prototype, redesain kursi, hilirisasi, eklektik

\section{Borobudur Chair Commercial Prototype Towards Downstream With The Eclectical Style Approach}

This article is based on the exploration of the reconstruction of the Borobudur Chair in the form of a replica which refers to the chair found in the Karmawibhangga relief of Borobudur Temple (2015) to go to stage 2 of downstream, 2020. The problem is 1) What is the prototype of the Borobudur Chair which can lead to downstreaming ? 2) Why is the Borobudur Chair prototype going downstream? 3) What is the shape of the Borobudur Chair which can lead to downstream? To get the answer to this question, a qualitative research was carried out, with a redesign (creation) process with consideration of design aspects (eclectic approach) in a cultural context, and a creative industry whose benefits could be felt for the community and the business world (downstream). The results and discussion are various commercial prototypes of Borobudur chairs that are ready to be produced in large quantities in the furniture craft industry. The advantage lies in the combination of various types of wood, stacking chairs (stackable), multi-functional (table side chairs, guest chairs, dining chairs, meeting chairs). In conclusion, the chairs developed from the reliefs of Borobudur Temple can be adjusted to the current developments. Suggestions for further research to collaborate with the furniture industry in producing Borobudur chairs related to downstream.

Keywords: prototype, chair redesign, downstream, eclectic

Proses Review : 2 - 28 Januari 2021, Dinyatakan Lolos: 16 Februari 2021 


\section{PENDAHULUAN}

Artikel ini diambil dari penelitian yang berjudul Prototype Komersial Kursi Borobudur Menuju Hilirisasi tahun 2020, yaitu tahun yang ke-2. Kajian yang merupakan kelanjutan dari Penelitian, Penciptaan, Penyajian Seni dan Desain (P3SD) tahun sebelumnya dengan judul yang sama, tahun 2019. Tahun 2019 menghasilkan prototype komersial kursi Borobudur menuju hilirisasi dengan pendekatan seni (lihat gambar 1). Seni dalam hal ini yang dimaksud adalah komunikasi antar manusia melalui penafsiran atas sebuah karya, dengan bahasa imaji yaitu imaji rupa, diolah bentuknya menjadi simbol penuh makna (Sugiharto, 2013: 35). Wujudnya lebih mengarah pada kebebasan ekspresi individu hasil dari respon pengolahan bentuk dari replika kursi Borobudur. Tahun 2020 ini dengan pendekatan desain khususnya eklektik lebih diarahkan ke desaindesain modern. Pendekatan seni dan desain sebenarnya ditujukan untuk memperluas peminat furniture khususnya kursi sehingga mendapatkan banyak pilihan wujud kursi. Prototype kursi adalah contoh produk kursi dengan standar dimensi dan ergonomi yang didesain melalui berbagai pertimbangan. Beberapa pertimbangan di antaranya berhubungan dengan desain dalam konteks budaya dan industri kreatif. Komersial dalam hal ini kursi didesain dan diproduksi dengan tujuan memperoleh keuntungan terkait dengan penjualannya.

The commercial prototype of Borobudur chairs towards hilirization aims at designing several alternative chairs in which ideas are from Borobudur chairs and reaching a commercial level in collaboration with the furniture industry to produce more chairs, have cheaper prices, and have effective and efficient distribution. Cultural considerations are important to reduce the aesthetic understanding gap between the designer and the user community (Widayat et al, 2020: 78).

Artinya kursi didesain mempertimbangkan karakter atau budaya konsumen. Kursi Borobudur adalah hasil riset sebelumnya berupa rekonstruksi jenis-jenis kursi yang terdapat pada relief Karmawibhangga Candi Borobudur. Karmawibhangga merupakan naskah yang menggambarkan ajaran sebab akibat perbuatan baik dan jahat (Marzuki dan Heraty, 1993: 42), jadi relief Karmawibhangga merupakan visualisasi dari ajaran sebab akibat perbuatan baik dan jahat. Relief Karmawibhangga terdiri dari 160 buah panel yang diperlihatkan untuk pengunjung hanya empat buah relief terletak sudut tenggara Candi (Mudhiuddin, 2009: 62). Sedangkan yang lainnya tertutup konstruksi, diperkirakan untuk penguat bangunan.

... banyak orang Belanda yang tertarik untuk meneliti dan menulis tentang Candi Borobudur. Salah seorang di antaranya adalah J.W. Ijzerman yang membuka kaki Candi Borobudur tahun 1885 dan menemukan sejumlah relief.
Pada tahun 1890 - 1891, kaki candi dibongkar untuk memungkinkan pemotretan. Secara hati-hati batu lantai dibongkar, untuk didokumentasikan foto lengkap dari seluruh panel, dan ditutup kembali. Pendokumentasian dilakukan secara lengkap oleh Kasian Chepas, seorang pribumi yang merupakan perintis fotografer Indonesia (Tim Penyusun, 2012: 1).

Penggambaran relief Karmawibhangga lebih mendekati kehidupan masyarakat zaman itu sekitar tahun 800 an Masehi. Sedangkan Candi Borobudur yang merupakan candi Buddha difungsikan sebagai tempat pemujaan (Soekmono, 1995: 83). Rekonstruksi kursi dari relief Karmawibhangga sudah dilakukan, selanjutnya diambil salah satu di antara kursi rekonstruksi yang lain dan dikembangkan untuk kepentingan industri furniture. Kursi dalam kajian ini pengertiannya fasilitas duduk yang mempunyai unsur-unsur kaki kursi, dudukan (tempat duduk satu dudukan atau lebih), ada yang menggunakan sandaran punggung, dan kadang-kadang dilengkapi dengan sandaran tangan. Kursi dalam konteks sosiologi seni mempunyai tingkatan dalam pemakaiannya, yaitu high art, folk art, dan popuar art (Hauser, 1982: 556). Artinya kursi mempunyai perbedaan wujud ketika digunakan oleh masyarakat golongan atas, kalangan masyarakat biasa, dan kursi yang dipakai karena tren. Berdasarkan relief Candi Borobudur dapat diketahui fasilitas duduk untuk Sang Buddha, orang-orang suci, para bangsawan, dan lain-lain. Menuju hilirisasi yaitu hasil penelitian ini ditujukan kepada penggunanya atau konsumen. Proses menuju konsumen melalui pendekatan desain yaitu berhubungan dengan estetika dan gaya. Faktor-faktor fungsi kursi, bahan-bahan yang digunakan, teknis konstruksi terkait produksi sehingga proses produksi menjadi penting. Prototype kursi dalam konteks desain dirancang dengan pertimbangan penggunanya, yaitu masyarakat masa kini yang mempunyai kecenderungan selera modern. Dengan demikian aspek budaya pengguna menjadi pertimbangan yang tidak dapat ditinggalkan, yang lebih cenderung memilih desain-desain yang serba praktis. Demikian juga bertalian dengan hilirisasi, pertimbangan sektor industri kreatif sangat diperlukan.

Posisi kajian dan penciptaan ini menjadi menarik untuk mengisi kekosongan produk kursi yang sumber idenya dari kursi yang digunakan lebih dari 1200 tahun yang lalu, mengingat Candi Borobudur dibangun pada sekitar tahun 800 Masehi (Joesoef, 2004: 7). Menjadi menarik kursi hasil redesain ini dihadirkan untuk kepentingan masyarakat modern sekarang ini.

Persoalannya adalah 1) Apa itu prototype Kursi Borobudur yang dapat menuju hilirisasi? 2) Mengapa prototype Kursi Borobudur menuju hilirisasi? 3) Bagaimana wujud Kursi Borobudur yang dapat menuju hilirisasi dengan pendekatan eklektik? 


\section{LITERATUR DAN TEORI}

Literatur berupa pendapat-pendapat yang digunakan untuk memperkuat argumentasi penulisan artikel ini, seperti tentang pertimbangan desain meliputi fungsi, bahan, teknis, estetis dalam konteks budaya dan industri kreatif. Kursi mempunyai fungsi untuk duduk, awalnya hanya digunakan oleh raja, ratu, dan orang-orang mulia lainnya (Jamaludin, 2007: 44). Saat ini kebiasaan duduk di kursi dengan berbagai karakter duduk sudah menjadi standar internasional, menghasilkan varian yang banyak. Hal ini memberi peluang bagi desainer dengan leluasa untuk mendesain berbagai macam wujud kursi.

Teori yang digunakan untuk membuat wujud desain yang baru, ialah teori eklektik. Eklektik yaitu memilih yang terbaik dari yang sudah ada sebelumnya (Sumalyo, 1997: 24). Berbicara tentan eklektik tidak lepas dari gaya. Gaya eklektik yang dimaksud adalah memilih, memadukan unsur-unsur atau gaya ke dalam bentuk tersendiri (Sumalyo, 1997: 24). Gaya sendiri mempunyai pengertian cermin perilaku dan sikap budaya manusia pada waktu tertentu, sejalan dengan dinamika kehidupan (Sachari, 1986: 96). Teori ini digunakan untuk memilih yang terbaik atau wujud yang mudah diingat dari kursi Borobudur dan memadukan dengan kursi-kursi gaya modern. Cara memadukannya dengan tetap mempertimbangkan satu-kesatuan wujudnya sehingga hasilnya terlihat tampil modern sesuai dengan kursi zaman sekarang. Hal ini berhubungan dengan pendapat pakar desain interior Solichin Gunawan, bahwa desain merupakan cerminan budaya zamannya (Sachari dan Sunarya, 2001: 10). Berdasarkan hal ini prototype kursi Borobudur menuju hilirisasi secara visual sebaiknya dekat dengan zaman sekarang.

\section{DATA AND METODE}

Data berupa rekonstruksi kursi pada relief Karmawibhangga Candi Borobudur, yang menghasilkan replika kursi Borobudur hasil penelitian sebelumnya pada tahun 2015, dipilih salah satu dan diperbaiki pada tahun 2018 yang dijadikan sebagai acuan. Kursi tersebut terdapat pada relief nomor 75 dari sejumlah 160 panel. Tafsir dalam teks dari relief tersebut adalah: Duduk di atas kursi, seorang bangsawan berbicara kepada orang-orang yang mendengarkan dengan khidmat (Tim Penyusun, 2012: 67).

Metode yang digunakan sesuai dengan jenis penelitian ini, yaitu penelitian, penciptaan, dan penyajian seni (P3S). Bagan alur proses menghasilkan prototype komersial kursi Borobudur menuju hilirisasi dengan pendekatan eklektik dapat dilihat pada gambar 2. Hasil penelitian berupa data di atas, sedangkan proses penciptaan dilakukan dengan pendekatan eklektik, untuk penyajiannya diikutsertakan dalam sebuah pameran. Pameran yang diikuti oleh dua puluh negara, yaitu International Visual Culture Exhibition \#3 yang diselenggarakan oleh Fakultas Seni Rupa dan Desain, Universitas Sebelas Maret, tahun 2020.

\section{HASIL DAN PEMBAHASAN}

Hasil dari kajian ini adalah membuat 5 (lima) buah desain kursi dan dibuat prototypenya. Lima buah desain kursi ini dipertimbangkan dari sisi fungsi, bahan, teknis, estetis dalam konteks budaya dan industri kreatif. Mengingat yang dikembangkan hanya kursi, maka fungsi kursi diharapkan dapat memenuhi berbagai variasi susunan fungsi duduk. Beberapa variasi kursi dipadukan dengan meja yang susunannya dapat dijelaskan seperti berikut. Kursi samping meja, yaitu dua buah kursi dengan meja di tengah-tengahnya (meja konsul). Meja dapat dibuat dengan ketinggian $74 \mathrm{~cm}$ dengan daun meja lebar 45 $\mathrm{cm}$ dan panjangnya $70 \mathrm{~cm}$, susunan ini diletakkan dekat dinding. Susunan lainnya sebagai kursi tamu, yaitu empat buah kursi mengelilingi sebuah meja. Meja untuk kursi tamu dapat dibuat serupa dengan coffee table atau meja untuk minum kopi, yaitu dengan standar ketinggian meja sekitar $58 \mathrm{~cm}$. Desain kursi ini dapat digunakan sebagai kursi makan, sedangkan susunannya sesuai dengan susunan meja dan kursi makan pada umumnya. Untuk meja makan yang akan dibuat secara desain lebih baik jika senada dengan kursinya sehingga dapat dicapai satu kesatuan atau unity. Desain kursi yang dibuat ini juga dapat difungsikan sebagai kursi untuk pertemuan, dan dapat disusun sesuai karakteristik pertemuan seperti untuk tempat duduk pengunjung dalam berbagai kegiatan, yakni rapat, seminar, hajatan dan lain-lain.

Proses desainnya dimulai dari replika hasil rekonstruksi kursi Borobudur, kemudian diredesain atau didesain ulang dengan pendekatan eklektik dengan memilih unsur yang mudah diingat yang terdapat pada kursi Borobudur. Selanjutnya dipadukan dengan konsep modern Form Follows Function atau bentuk mengikuti fungsi, yang terdapat pada kursi yang sudah eksis lebih dahulu. Intinya menggabungkan unsur kursi Borobudur yang telah dimodifikasi disesuaikan dengan karakter kursi modern. Proses perwujudan selanjutnya mempertimbangkan bahan yang digunakan, teknis konstruksi, keindahan, budaya, dan industri kreatif (lihat gambar 3).

Bahan yang digunakan untuk pembuatan prototype komersial kursi Borobudur ini dari bahan campuran, dengan tujuan untuk menghadirkan variasi warna dalam sebuah kursi untuk menghindari kesan monoton. Selain itu juga untuk menunjukkan kemampuan teknis yang tinggi karena secara teknik dapat memadukan bahan yang berbeda menjadai satu, sekaligus menunjukkan ketekunan dan ketelitian dalam memadukan bahan. Bahan-bahan yang digunakan adalah kayu mahoni, jati Belanda, jati, dan sonokeling. Bahan pendukung untuk konstruksi adalah pipa kuningan $1 / 2$ dim. Dudukan kursi dapat juga ditambah dengan pengempuk yang menggunakan busa dan upholstery dari bahan semi sintetik. Untuk finishing kayu menggunakan teak oil atau clear water based. Teknik yang digunakan untuk sambungan atau joint 
menggunakan pasak dan purus, penguwat dowel, dan lem. Penggunaan lem dan pengepresan bahan kayu sangat penting untuk memadukan berbagai jenis bahan yang berbeda, sehingga mengasilkan sambungan yang presisi dan rata seolah-olah satu bahan.

Estetika menjadi pertimbangan yang penting berhubungan dengan wujud desain. Estetika atau keindahan dari kursi yang dibuat adalah hasil dari penggabungan unsur-unsur yang dipilih antara replika kursi Borobudur dengan desain kursi-kursi modern yang mengarah pada konsep Form Follow Fuction atau bentuk mengikuti fungsi nya Louis Henry Sullivan. Jika kebutuhan fungsional dapat dipenuhi secara tepat, keindahan akan mengikuti secara logis (Walker, 2010: 220). Secara estetis prototype komersial kursi Borubudur menuju hilirisasi mempertahankan salah satu karakter kursi Borobudur untuk dikombinasikan dengan kursi-kursi modern (lihat gambar 4). Hal ini sesuai dengan salah satu cara membuat bentuk yaitu mengkombinasikan dengan bentuk-bentuk yang ada (Susanto, 2012: 105).

Konsep mengkombinasikan secara eklektik ini sudah menjadi bagian dari sejarah, khususnya dalam dunia arsitektur sudah ada sejak lama. Pada zaman Renaissance, kolom, ornamen digabungkan dan ditambah dengan unsurunsur, kaidah dan bentuk baru. Jauh sebelumnya arsitektur Romawi klasik juga mengambil unsur-unsur dari arsitektur Yunani klasik menjadi bentuk baru (Sumalyo, 1997: 24). Artinya tidak ada yang salah dengan penggunaan teori atau cara eklektik untuk menghasilkan bentuk-bentuk baru. Di Jawa khususnya Surakarta tepatnya pada bangunan Keraton Kasunanan Surakarta dan Kadipaten Mangkunegaran banyak dijumpai kombinasi unsur-unsur bangunan Eropa dengan Jawa, seperti atap Joglo, Limasan disangga dengan tambahan tiang-tiang bangunan Yunani seperti Ionic dan Doric dan juga Neo-Klasik. Konsep ini dalam konteks budaya Jawa masuk dalam katagori à̀ng atau aneh atau ora njawani dalam hal ini bukan Jawa (Widayat, 216: 2016: ). Konsep aèng dalam hal ini bukan berarti tidak bagus atau jelek, namun sebaliknya dapat menghasilkan bentuk-bentuk baru yang mewarnai zamannya, yaitu zaman di mana Jawa atau Indonesia saat itu sedang dijajah oleh bangsa Belanda. Orang-orang Belanda membawa budaya Eropa yang berkembang saat itu untuk diterapkan di tanah jajahannya. Konsep aèng banyak menghadirkan bentuk-bentuk baru, seperti rupa Pawukon, yaitu wuku dan dewanya digambarkan dengan rupa wayang purwa (wayang kulit), namun bentuk rumahnya dirupakan dengan dengan bangunan gaya Romawi Kuno.

Wuku Kuwalu with its god Batara Sadana in a twodimensional form are combined with some figures like buildings, floors, water, trees, birds, spears and their sheath) made in three dimensions. The shape of the building in pawukon figuresis generally inspired by the appearance of Javanese house roofs, but the presentation of the building in this wuku is in Roman style complete with traps (cripedoma), doric poles, and pediment forms (triangular wall construction), and is equipped with dome (domes). This particular pawukon figure with its two-dimensional wuku presentation and deity characters feels aeng (strange) with supporting shapes of threedimensional forms, and that the building's shape is not Javanese but Roman-style (Widayat dan Studyanto, 2018: 426).

Berhubungan dengan pendapat-pendapat yang mempunyai perhatian terhadap budaya Jawa seperti Umar Kayam dan Toeti Heraty Noerhady perubahan tersebut berhubungan dengan sikap kreatif. Sikap kreatif berarti: bergairah untuk memikirkan, mencari, menemukan, menciptakan yang baru dan sebaiknya ditanggapi secara positif(Suseno, 1991: 86). Bertalian dengan desain interior kontemporer di kotakota besar di Indonesia, khususnya Jakarta marak interior bergaya eklektik yaitu campuran modern dan tradisional (Hidayat, 2006: 103). Artinya konsep eklektik sebagai solusi dalam mengkombinasikan elemen-elemen visual dari berbagai sumber, banyak dilakukan.

Karakter kursi Borobudur yang dipilih adalah bagian atas sandaran punggung menonjol ke luar, jika diamati outline nya dapat ditafsirkan menyerupai bentuk kalamakara. Kalamakara merupakan makhluk khayalan penggabungan dari kala atau kepala Banaspati dengan makara atau gubahan belalai gajah dan kepala singa, dengan badan berbentuk ular. Kalamakara mempunyai fungsi sebagai tolak balak, tolak artinya menolak, balak artinya bahaya, jadi sebagai penolak bahaya (Widayat, 2017: 31, 32). Bertalian dengan ditempatkannya pada kursi mempunyai tujuan agar yang duduk di kursi terhindar dari bahaya yang tidak diinginkan.

Kursi Borobudur dalam konteks budaya dapat dilihat sebagai warisan yang dialih-diturunkan dari generasi satu ke generasi berikutnya (Sutrisno dan Putranto, 2005: 9). Kursi Borobudur yang merupakan warisan "tanpa surat wasiat" ini penting untuk dilestarikan dalam rangka menyambung benang merah yang terputus dari generasi masa lalu ke generasi masa kini. Selanjutnya sebagai penghargaan terhadap budaya yang pernah hidup ribuan tahun yang lalu pada zamannya nenek moyang untuk generasi sekarang. Melalui kursi Borobudur ini terselip pesan budaya yang harapannya sampai kepada masyarakat zaman sekarang, yakni simbol strata sosial sesuai budaya zaman seperti berikut ini.

Research on creative industry products needs to be done continuously and developed into products that have a cultural message that affect the user. The Borobudur chair we studied is rich in cultural messages from the 8th century, where the Javanese sitting culture at that time was very varied and rich with the symbols of the social strata in accordance with the culture of that time (Widayat, 2020: 
462).

Kursi Borobudur jika sudah memasuki tahap hilirisasi atau memasuki dunia industri menjadi bagian industri kreatif. Industri kreatif terdiri dari 16 bidang, 7 bidang terkait dengan ranah seni. Hal itu termasuk arsitektur; pasar barang seni dan antik, kriya; desain, desain fashion; film; seni (rupa); suara; pertunjukan (Zaman, 2012: 1). Redesain kursi Borobudur dengan menekankan pada nilai komersial dan menuju hilirisasi bagian dari desain dalam industri kreatif. Desain komersial dari kursi Borobudur, sebagai sarana melakukan penemuan baru terkait kegiatan industri dan bisnis (Bruce Nussbaum, dalam Sachari dan Sunarya, 2002: 5). Bisnis dalam kontek prototype komersial kursi Borobudur menuju hilirisasi lebih menekankan pada keuntungan berdasarkan produk kursi yang terjual.

\section{SIMPULAN}

Berdasarkan permasalahan yang ada dan hasil pembahasannya dapat disimpulkan bahwa prototype kursi Borobudur yang dapat menuju hilirisasi adalah redesain replika kursi Borobudur yang sesuai dengan kepentingan zaman sekarang. Prototype komersial kursi Borobudur menuju hilirisasi adalah agar dapat dimanfaatkan oleh pengguna zaman sekarang. Dengan memanfaatkan kursi tersebut dapat mendukung pelestarian warisan nenek moyang yang digunakan lebih dari 1200 tahun yang lalu. Atau berusaha menyambung kembali benang merah yang telah terputus dan membuktikan bahwa nenek moyang kita juga mempunyai budaya duduk di kursi. Selain itu jika produk komersial kursi Borobudur menuju hilirisasi nantinya mendapat sambutan dari masyarakat, hal ini mengindikasikan harapan untuk mendapatkan keuntungan finansial dari usaha untuk meredesain kursi Borobudur ini. Mengenai wujud kursi Borobudur yang dapat menuju hilirisasi dengan pendekatan eklektik, yaitu memadukan unsur kursi Borobudur yang mudah dikenali dikombinasikan dengan konsep kursi modern yaitu Form Follow Function atau bentuk mengikuti fungsi, dengan tujuan agar lebih dekat dengan kultur masyarakat zaman sekarang.

Saran untuk penelitian selanjutnya, yaitu dapat mengembangkan dalam tahap hilirisasi dan fokus pada kerja sama dengan dunia industri furniture, baik skala kecil, menengah, atau besar tergantung prospeknya yang paling bagus dan menjanjikan dari sisi bisnis. Dari sisi kepentingan masyarakat seputar Candi Borobudur yang bergerak di bidang furniture, dapat menggunakan konsep eklektik ini untuk mengembangkan usahanya. Artinya apa yang dilakukan tidak semata-semata untuk kepentingan pribadi peneliti, namun juga untuk masyarakat luas yang bersinggungan dengan Candi Borobudur.

\section{UCAPAN TERIMA KASIH}

Ucapan terimakasih kepada Rektor dan Kepala Lembaga Penelitian dan Pengabdian Kepada Masyarakat Universitas Sebelas Maret, yang telah membiayai penelitian yang dijadikan rujukan untuk penulisan artikel ini dengan dana PNBP (Penerimaan Negara Bukan Pajak), dengan skema Penelitian, Penciptaan, Penyajian Seni dan Desain (P3SD), tahun 2020.

\section{DAFTAR RUJUKAN}

Hauser, Arnold. 1982. The Sosiology of Art. Terj. Kenneth J. Northcott. Chicago: The University of Chicago.

Hidayat, July. 2006. "Kode Ganda dalam Desain Interior Kontemporer: Suatu Kajian Post Kolonial”. Artikel dalam Jurnal Ilmu Desain, FSRD ITB Vol 1 No 2. Hal. 103 - 114.

Jamaludin. 2007. Pengantar Desain Mebel. Bandung: PT Kiblat Buku Utama.

Joesoef, Daoed. 2004. Borobudur. Jakarta: Penerbit Buku Kompas.

Marzuki, Yasir dan Heraty, Toety. 1993. Borobudur. Jakarta: Penerbit Djambatan.

Mudhiuddin, Andi M., 2009. Borobudur Prambanan dan Candi Lainnya: Menelusuri Jejak Peradapan Jawa. Yogyakarta: Kreasi Wacana.

Sachari, Agus dan Sunarya, Yan Yan. 2002. Sejarah dan Perkembangan Desain dan Dunia Kesenirupaan di Indonesia. Bandung: Penerbit ITB.

Sachari, Agus dan Sunarya, Yan Yan. 2001. Desain dan Dunia Kesenirupaan Indonesia dalam Wacana Transformasi Budaya. Bandung: Penerbit ITB.

Sachari, Agus. 1986. Desain Gaya dan Realitas: Sebuah penafsiran tentang Desain Grafis, Produk, Interior, Tekstil, dan Arsitektur di Indonesia. Jakarta: CV. Rajawali.

Soekmono, R. 1995. Pengantar Sejarah Kebudayaan Indonesia 2. Yogyakarta: Penerbit Kanisius.

Sugiharto, Bambang. 2013. "Seni dan Dunia Manusia", dalam Buku: Untuk Apa Seni, Editor Bambang Sugiharto. Bandung: Penerbit Matahari, halaman 15-43.

Sumalyo, Yulianto. 1997. Arsitektur Modern Akhir Abad XIX dan Abad XX. Yogyakarta: Gadjah Mada University Press. 
Susanto, Mikke. 2012. Diksi Rupa Kumpulan Istilah dan Gerakan Seni Rupa. Yogyakarta: DictiArt Lab \& Djagad Art House.

Suseno, Franz Magnis. 1991. Wayang dan Panggilan Manusia. Jakarta: PT Gramedia Pustaka Utama.

Sutrisno, Mudji dan Putranto, Hendar. 2005. Teori-Teori Kebudayaan. Yogyakarta: Kanisius.

Tim Penyusun, 2012. Adegan dan Ajaran Hukum Karma pada Relief Karmawibhangga. Magelang: Balai Konservasi Borobudur.

Walker, John A. 2010. Desain, Sejarah, Budaya; Sebuah Pengantar Komprehensif. Terjemahan: Design History and The History of Design (1989). Penerjemah: Laily Rahmawati. Yogyakarta: Penerbit Jalasutra.

Widayat, Rahmanu, dkk. 2015. Rekonstruksi "Kursi Borobudur" (Untuk Menunjang Industri Kreatif), Penelitian Unggulan Perguruan Tinggi (PUPT) Tahap I, Fakultas Seni Rupa dan Desain, Universitas Sebelas Maret Surakarta.

Widayat, Rahmanu, 2016, Estetika Barang Kagunan Interior Dalem Ageng di Rumah Kapangéranan Keraton Surakarta, Disertasi Program Pascasarjana Institut Seni Indonesia (ISI) Surakarta.

Widayat, Rahmanu. 2017. Ragam Hias Bangunan Keraton Surakarta. Surakarta: UNS Press.

Widayat, Rahmanu and Studyanto, Anung B., (2018). Wangun Visual Concept In Pawukon Figures And Interior Design Contexts. Mudra Jurnal Seni Budaya, 33(3), 421429. https://doi.org/10.31091/mudra.v33i3.546

Widayat, Rahmanu, dkk. 2019. Prototype Komersial Kursi Borobudur Menuju Hilirisasi. Tahap I. Penelitian, Penciptaan, Penyajian Seni dan Desain (P3SD) dana PNBP Universitas Sebelas Maret Surakarta.

Widayat, Rahmanu, et al. 2020. Commercial Prototype of Borobudur Chair Towards Hilirisasi. Research Article in Proceedings of the 1st Conference of Visual Art, Design, and Social Humanities by Faculty of Art and Design, CONVASH 2019, November 02, Surakarta, Central Java, Indonesia. Copyright (C) 2020 EAI DOI 10.4108/eai.2-112019.2294943. Page 75-78.

Widayat, Rahmanu, dkk. 2020. Prototype Komersial Kursi Borobudur Menuju Hilirisasi. Tahap II. Penelitian, Penciptaan, Penyajian Seni dan Desain (P3SD) dana PNBP Universitas Sebelas Maret Surakarta.
Widayat, Rahmanu. 2020. Redesigning the Borobudur chair to sustain local creative industries: introducing to wangun concept. International Journal of Engineering \& Technology, 9 (2) (2020) 458-463. Website: www. sciencepubco.com/index.php/IJET

Zaman, Biranul Anas. 2012. "Jurus Cendekia dalam Industri Seni Menyiasati Ekonomi Kreatif-SeniPariwisata", Artikel dalam Prosiding Seminar Nasional Perguruan Tinggi Seni Dalam Era Ekonomi KreatifProgram Pascasarjana ISI Surakarta. Surakarta: ISI Press 


\section{DAFTAR GAMBAR}

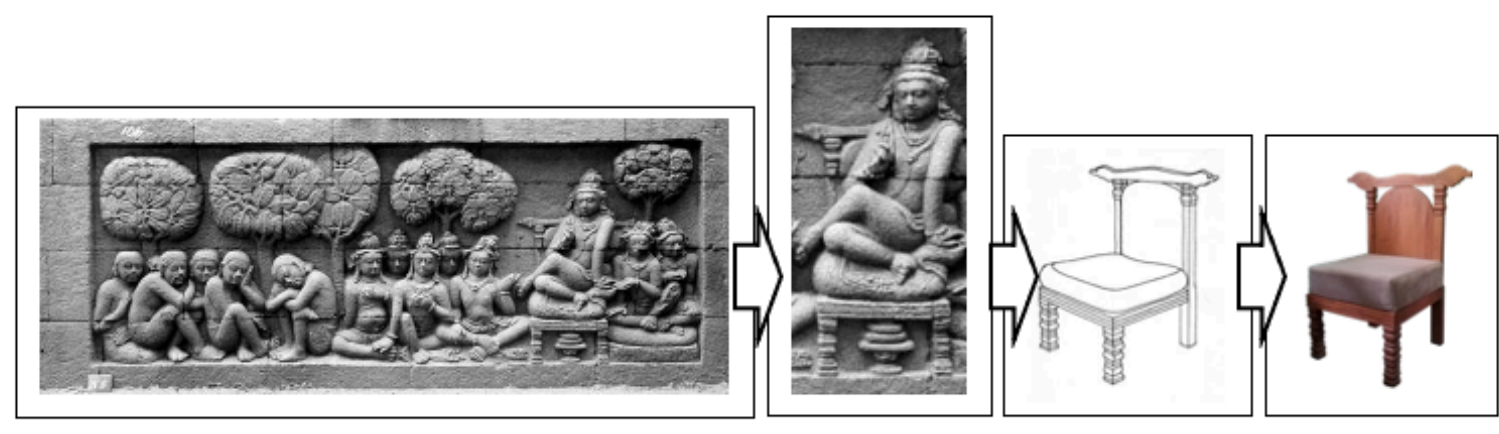

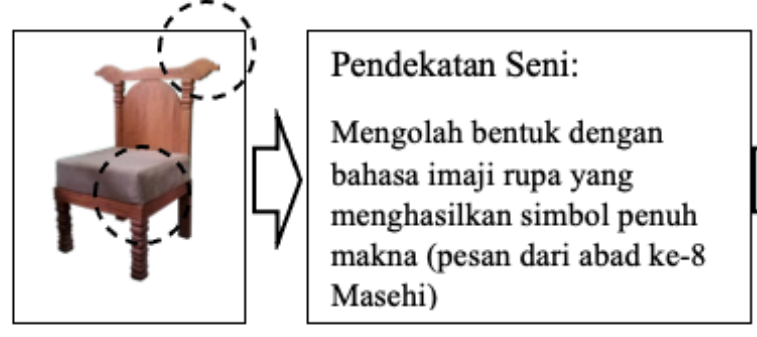

Replika

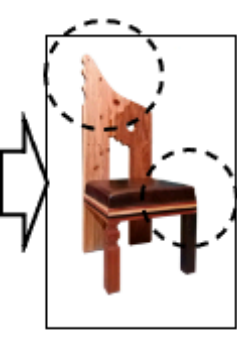

Kursi 1

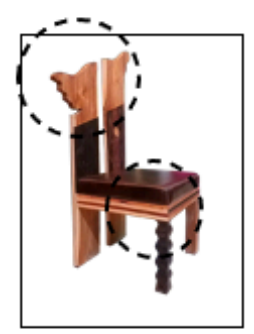

Kursi 2

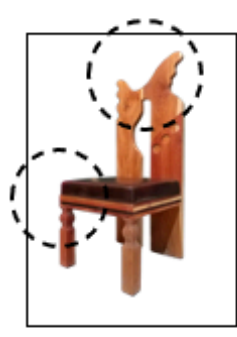

Kursi 3

Gambar 1. Proses dari replika Kursi Borobudur menjadi prototype komersial menuju hilirisasi dengan pendekatan seni (Sumber: Penulis, 2019)

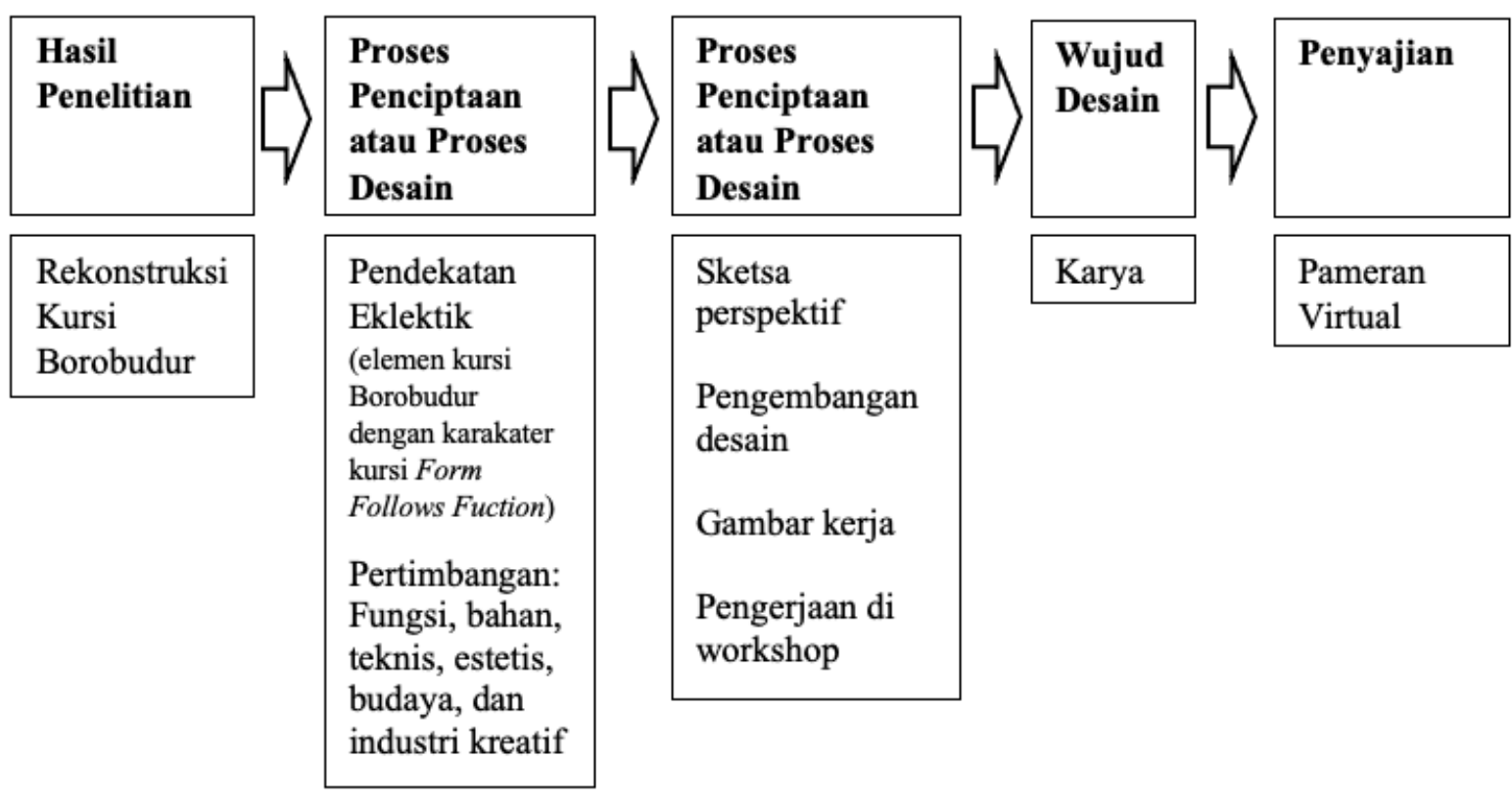

Gambar 2. Bagan alur proses menghasilkan prototype komersial kursi Borobudur menuju hilirisasi dengan pendekatan eklektik, skema P3SD (Sumber: Penulis, 2020) 

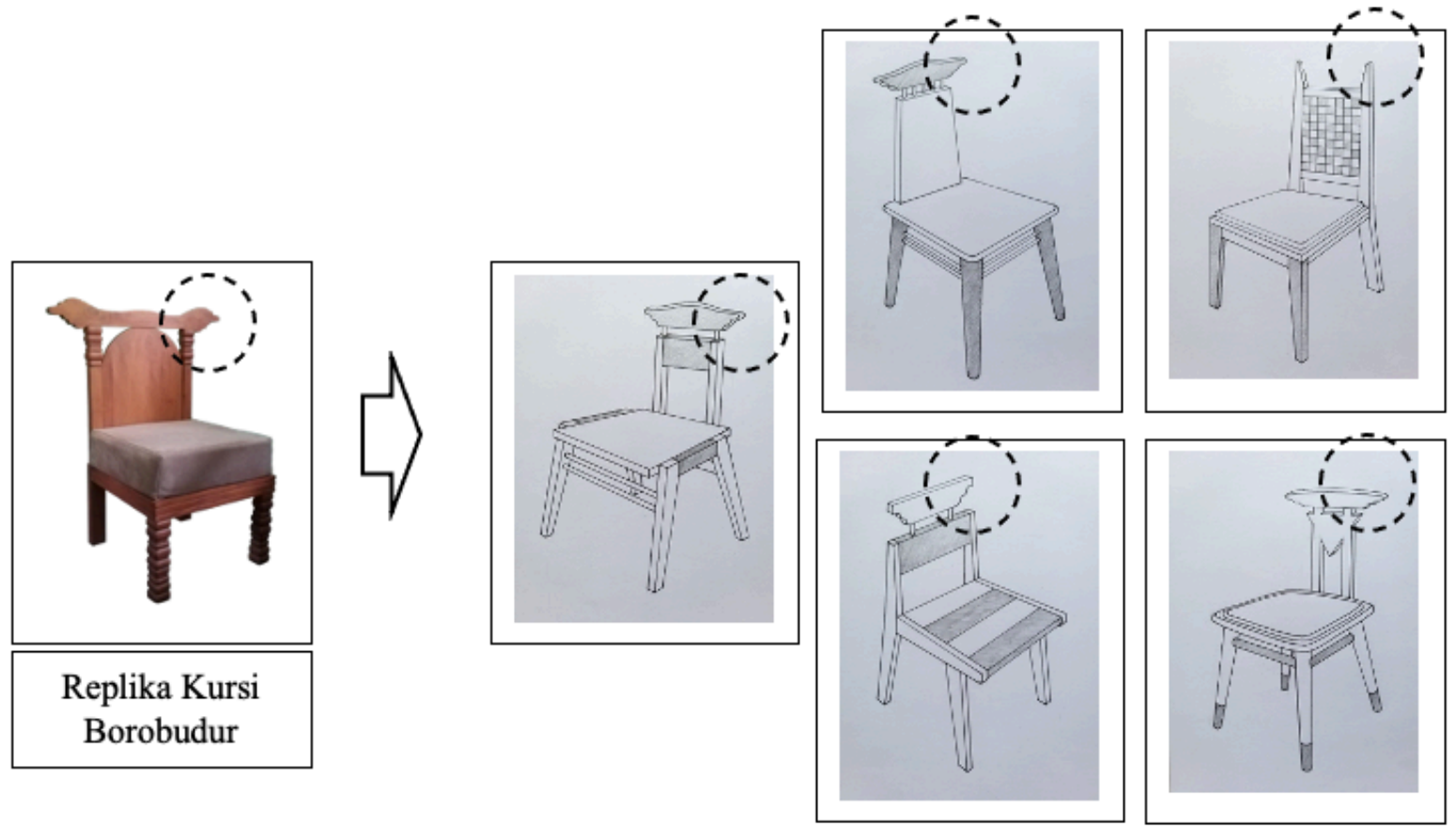

Gambar 3. Kursi Borobudur dan prototype komersial menuju hilirisasi berupa lima buah sketsa perspektif dengan memadukan unsur bagian kiri kanan atas sandaran pada kursi Borobudur dengan kursi modern, sebagai proses eklektik (Sumber: Penulis, 2020)
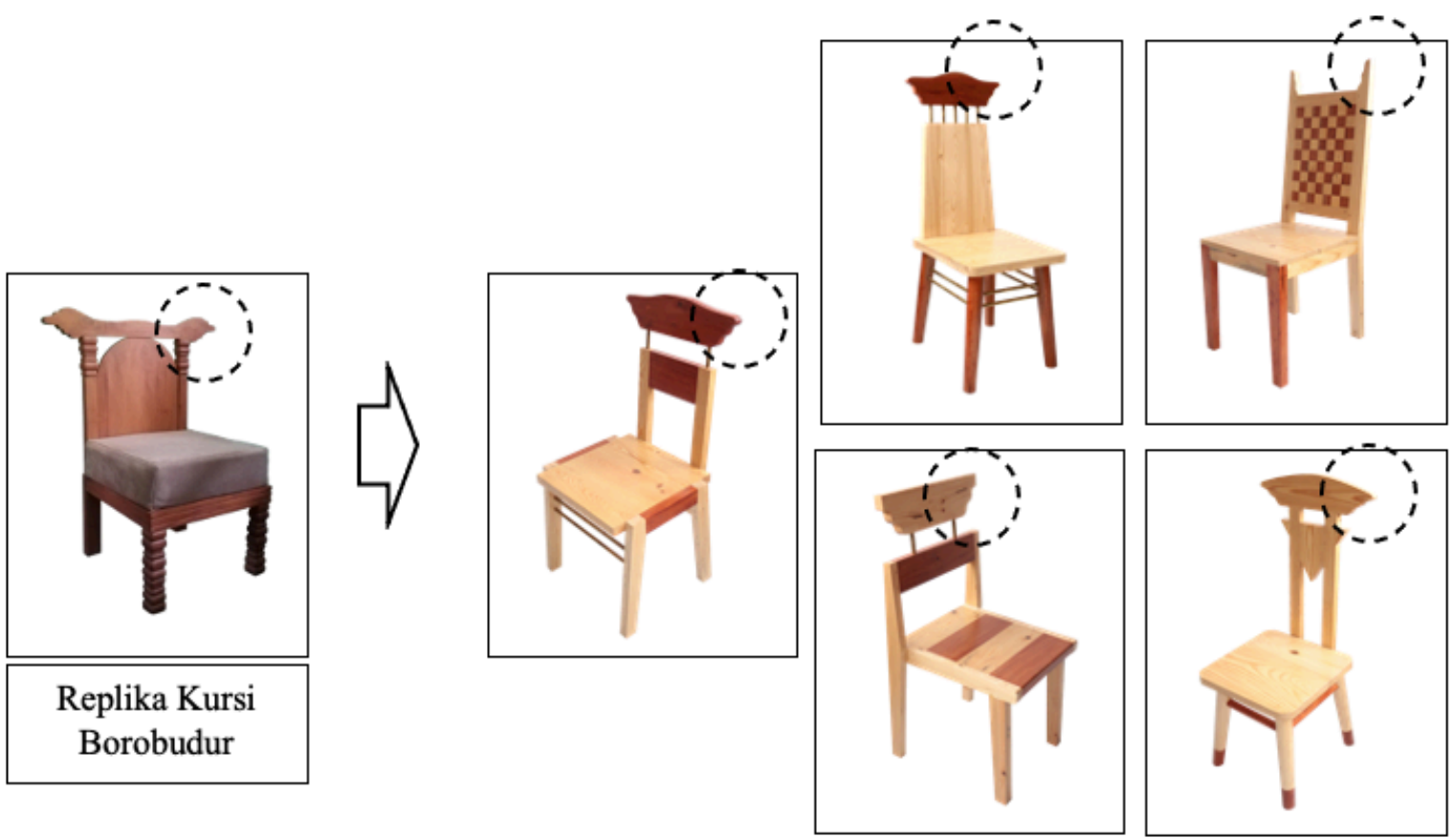

Gambar 4. Kursi Borobudur dan prototype komersial menuju hilirisasi berupa lima model kursi perpaduan unsur bagian atas sandaran kursi Borobudur dengan kursi modern, hasil proses eklektik (Sumber: Penulis, 2020) 